\title{
Prevalence of glucose abnormalities in polycystic ovary syndrome women and evaluating the efficacy of fasting blood glucose in detecting these glucose abnormalities compared to glucose tolerance test
}

\author{
Swarnalatha Mohanapu*, Abinaya Maathuri Jeyakumar
}

Department of Obstetrics and Gynaecology, SRM Medical College Hospital and Research Institute, Kattankulathur, Tamil Nadu, India

Received: 09 April 2019

Accepted: 13 April 2019

\section{*Correspondence:}

Dr. Abinaya Maathuri Jeyakumar,

E-mail: drabinaya001@gmail.com

Copyright: () the author(s), publisher and licensee Medip Academy. This is an open-access article distributed under the terms of the Creative Commons Attribution Non-Commercial License, which permits unrestricted non-commercial use, distribution, and reproduction in any medium, provided the original work is properly cited.

\section{ABSTRACT}

Background: Polycystic ovarian syndrome (PCOS) is the most commonly prevalent endocrinopathy of reproductive age women. It is a significant public health issue with reproductive, metabolic and psychological features. Because patients with PCOS are at high risk for developing glucose abnormalities, the early identification of affected patients and institution of life style changes or pharmacological treatment may help reduce the long-term risks associated with PCOS. This study was done to assess the prevalence of glucose abnormalities and to evaluate the efficacy of Fasting blood glucose (FBG) in detecting glucose abnormalities when compared to 2 hrs oral glucose tolerance test (OGTT).

Methods: Hospital based cross sectional study carried out in 300 women diagnosed as PCOS according to Rotterdam criteria. In patients diagnosed as PCOS, Fasting Blood Glucose and OGTT were done. OGTT taken as an accurate test and FBG values compared with OGTT values to evaluate the efficacy of FBG. Prevalence of glucose abnormalities and association with age, BMI and clinical features was evaluated.

Results: Glucose abnormalities were detected in 69 (23\%) women with 2 hours OGTT, but with FBG only in 49 $(16.33 \%)$ women, around one third of women were missed. Sensitivity of FBG was $71.01 \%$ (95\% CI $58.84 \%$ to $81.31 \%$ ). Mean age of women with abnormal OGTT (27.99) was significantly higher than the women with normal OGTT (24.7). Mean BMI of women with abnormal OGTT (27.42) was significantly higher than the Mean BMI of women with normal OGTT (23.36).

Conclusions: Sensitivity of FBG was low in detecting glucose abnormalities. Increasing age, increase in a BMI, menstrual abnormalities, hirsutism/acne and family history of diabetes appear to have positive linear correlation with prevalence of glucose abnormalities.

Keywords: Fasting blood glucose, Glucose abnormalities, OGTT, PCOS

\section{INTRODUCTION}

The polycystic ovarian syndrome is the single most common endocrine disorder of reproductive age women, characterised by chronic anovulation/ oligomenorrohea, hyperandrogenism and insulin resistance. The association of amenorrohea and bilateral polycystic ovaries and obesity was first described in 1935 by Stein and Leventhal. The syndrome is present in approximately 15 to $20 \%$ of reproductive age women. These women present with diverse features including reproductive (irregular menstrual cycles, hirsutism, infertility and pregnancy complications), metabolic (insulin resistance, metabolic syndrome, pre-diabetes, type 2 diabetes and 
cardio vascular risk factors) and psychological ( anxiety, depression, body image). ${ }^{1-4}$ Therefore, identifying PCOS and screening for these adjunct disorders will allow for timely institution of preventive strategies aimed at minimizing the overall health risks. Impaired glucose tolerance (IGT) is a known risk factor for type 2 diabetes and development of cardiovascular disease. ${ }^{5}$ As most of women present at young age and IGT being asymptomatic, it is important to screen and identify pre diabetes and diabetes. Controversy around the optimal screening test to detect glucose abnormalities in PCOS is significant with proposed benefit of identifying IGT on an OGTT, requiring balance with increased inconvenience, cost and poor reproducibility with FBG which is more convenient, less costly more reproducible and easier to perform. Therefore, the present study was conducted to assess the prevalence of glucose abnormalities in patients with PCOS and to evaluate the efficacy of FBG in detecting glucose abnormalities.

\section{METHODS}

This study was conducted in SRM Medical College Hospital and Research Institute for a period of 2 years between October 2016 to December 2018. It was a hospital based analytical cross-sectional study, carried out in 300 women between age group of 18 to 35 years who were diagnosed as PCOS according to Rotterdam criteria (The Rotterdam ESHRE/ ASRM sponsored consensus workshop group 2004). ${ }^{6}$ Two of the following criteria required to confirm the diagnosis of PCOS after exclusion of other causes.

- Oligo/anovulation (less than 8 cycles per year),

- Hyperandrogenism-clinical (hirsutism or less commonly male pattern alopecia) or biochemical (raised free androgen index or free testosterone),

- Polycystic ovaries on ultra sound (at least one ovary with 12 follicles of size 2 to $9 \mathrm{~mm}$ and or increased ovarian volume of more than $10 \mathrm{ml}$ ).

Women with PCOS already diagnosed with glucose abnormalities, women using insulin sensitizers or drugs affecting lipids, weight or insulin sensitivity within 3 months, women with prolactin and thyroid abnormalities, women with systemic illness and women who were not willing to participate were excluded. After exclusion total 300 women were enrolled for the study. Ethical clearance was obtained from the institutional ethical committee and informed consent was taken from each participant.

Detailed history regarding menstrual cycles, acne, hirsutism, marital status, parity, duration of infertility, history of gestational diabetes, drug history, family history of Type 2 diabetes taken from each patient. Standard anthropometric data including height, weight, blood pressure was measured. Degree of hirsutism was assessed by modified Ferriman- Gallwey- Lorenzo score. A score of more than or equal to 4-6 was considered as abnormal. ${ }^{7}$ BMI was calculated and women were categorized according to ICMR guidelines in the following way. ${ }^{8}$ Normal between 18 to $22.9 \mathrm{~kg} / \mathrm{m}^{2}$, overweight between 23 to $24.9 \mathrm{~kg} / \mathrm{m}^{2}$, and obese if BMI is more than $25 \mathrm{~kg} / \mathrm{m}^{2}$. FBG was obtained, then 2 hours OGTT was performed with $75 \mathrm{gm}$ anhydrous glucose dissolved in 200 to $300 \mathrm{ml}$ of water and the blood sample was taken after 2 hours. Glucose abnormalities were diagnosed according to ADA criteria. ${ }^{9}$

- $\quad$ FBG <100 mg/dl- Normal, 100 to $125 \mathrm{mg} / \mathrm{dl}-$ Impaired fasting blood glucose, $\geq 126 \mathrm{mg} / \mathrm{dl}$ - Type 2 diabetes.

- 2 hours OGTT <140- Normal, 140 to $199 \mathrm{mg} / \mathrm{dl}-$ impaired glucose tolerance, $\geq 200 \mathrm{mg} / \mathrm{dl}$ - Type 2 diabetes.

Descriptive analysis was carried out by mean and standard deviation for quantitative variables. Data was also represented by appropriate diagrams like bar diagrams. The efficacy of FBG in detecting glucose abnormalities considering OGTT as gold standard was analysed by calculating sensitivity, specificity, predictive values and diagnostic accuracy of FBG with $95 \%$ CI.

\section{RESULTS}

\section{Demographic features}

The mean age of study population was $25.5 \pm 5.6$, the mean age of women with normal OGTT was $24.7 \pm 3.2$ and the mean age of abnormal OGTT was found to be higher 27.99 \pm 4.3 (Table 1).

Table 1: Age and BMI.

\begin{tabular}{|lllll|}
\hline Variable & $\begin{array}{l}\text { Mean } \pm \text { SD of study } \\
\text { population }(\mathrm{n}=300)\end{array}$ & $\begin{array}{l}\text { Mean } \pm \text { SD of women with } \\
\text { normal OGTT }(\mathrm{n}=231)\end{array}$ & $\begin{array}{l}\text { Mean } \pm \text { SD of women with } \\
\text { abnormal OGTT }(\mathrm{n}=69)\end{array}$ & $\begin{array}{l}\text { P value } \\
\text { (One-way ANOVA })\end{array}$ \\
\hline Age & $25.5 \pm 5.6$ & $24.7 \pm 3.2$ & $27.99 \pm 4.3$ & $\mathrm{P}<0.01$ \\
\hline BMI & $24.29 \pm 0.9$ & $23.36 \pm 0.7$ & $27.42 \pm 0.88$ & $\mathrm{P}<0.01$ \\
\hline
\end{tabular}

Among 300 women in this study, 133 women had normal BMI. 61 women had over weight BMI and 106 women were obese. Abnormal OGTT was found in $6(4.5 \%)$ of women with normal BMI ( $\mathrm{n}=133), 16(26.22 \%)$ of 
women with overweight BMI ( $\mathrm{n}=61)$ and $47(44.33 \%)$ of women with obesity respectively (Figure 1).

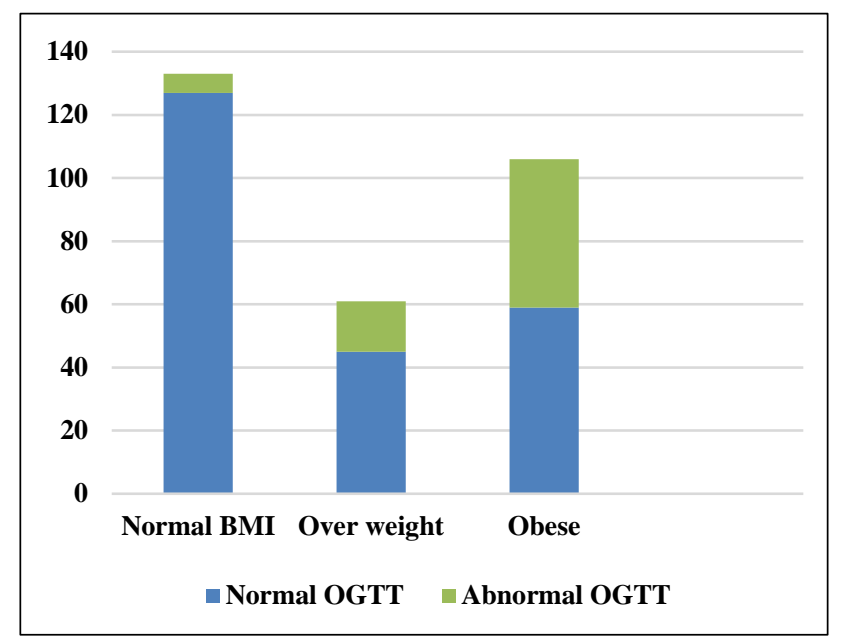

Figure 1: BMI and abnormal OGTT.
The mean BMI of total study population was $24.29 \pm 0.9$, the mean BMI of women with normal OGTT was $23.36 \pm 0.7$ and the mean BMI of women with abnormal OGTT was higher 27.42 \pm 0.88 . Mean BMI values are depicted in Table 1.

\section{Clinical presentation}

In this study, 198 women were presented with menstrual irregularities out of which 135 women (68.18\%) had normal OGTT, 63 women $(31.81 \%)$ had abnormal OGTT. Hirsutism was present in 117 of study population out of which $30(25.64 \%)$ women had abnormal OGTT, the remaining 87 women $(74.35 \%)$ had normal OGTT. Family history of diabetes was present in 71 women out of which 35 women (49.29\%) had abnormal OGTT and 36 women $(50.70 \%)$ had normal OGTT. There appear to be a positive linear correlation between menstrual irregularities, hirsutism/ acne and family history of diabetes (Figure 2).

Table 2: Clinical presentation and OGTT.

\begin{tabular}{|llll|}
\hline $\begin{array}{l}\text { Clinical } \\
\text { feature }\end{array}$ & $\begin{array}{l}\text { No. of persons with the } \\
\text { clinical feature Yes/No }\end{array}$ & $\begin{array}{l}\text { No. of women with } \\
\text { abnormal OGTT }\end{array}$ & $\begin{array}{l}\text { Percentage of patients with abnormality } \\
\text { (column 3/column 2x 100) }\end{array}$ \\
\hline $\begin{array}{l}\text { Menstrual } \\
\text { Hirsutismormality }\end{array}$ & Yes, $\mathrm{n}=198$ & 63 & $31.81 \%$ \\
\cline { 2 - 4 } & No, $\mathrm{n}=102$ & 6 & $5.88 \%$ \\
\hline \multirow{2}{*}{ Family h/o DM } & Yes, $\mathrm{n}=117$ & 30 & $25.64 \%$ \\
\cline { 2 - 4 } & No, $\mathrm{n}=183$ & 39 & $21.31 \%$ \\
\cline { 2 - 4 } & Nos, $\mathrm{n}=71$ & 35 & $49.29 \%$ \\
\hline
\end{tabular}

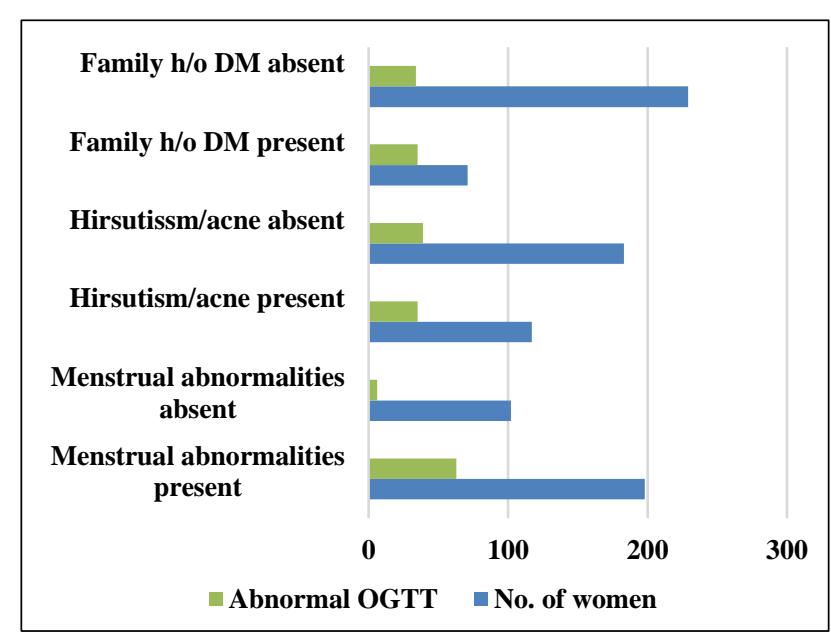

Figure 2: clinical features and abnormal OGTT.

\section{Fasting blood glucose vs OGTT}

Among 300 women OGTT was normal in 231 (77\%) women and abnormal in $69(23 \%)$ women, among 69 women with abnormal OGTT values, impaired glucose tolerance was seen in $65(21.66 \%)$ and diabetes in 4 (1.33\%) women. Among 300 women FBG values were normal in $227(75.66 \%)$ women and abnormal in 53 (17.66\%), among 53 women with abnormal FBG values, impaired fasting glucose was seen in $50(16.66 \%)$ women and diabetes was seen in $3(1 \%)$ women.

Among 231 subjects with normal OGTT, FBG values were also normal in 227 subjects but abnormal in 4 subjects. Among 69 subjects with abnormal OGTT, FBG values were abnormal only in 49 subjects and in remaining 20 subjects FBG values were normal (Table 3 and Figure 3).

The sensitivity of FBG in assessing glucose abnormalities was lower $71.01 \%$ (95\% CI $58.84 \%$ to $81.31 \%$ ) and the specificity was $98.27 \%$ (95\% CI 95.63\% TO 99.53\%). The positive predictive value was $92.45 \%$ (95\% CI $82.09 \%$ to $97.04 \%$ ). The negative predictive value was $91.90 \%$ (95\% CI $88.69 \%$ to $94.26 \%)$. The overall diagnostic accuracy was $92.00 \% \quad(95 \% \mathrm{CI} 88.33 \%$ to 94.81\%) (Table 4). 
Table 3: Fasting blood glucose test with standard OGTT.

\begin{tabular}{|lcll|}
\hline OGTT (No.) & F BG (No.) & Abnormal \\
\hline Normal & 231 & 227 (true negative) & $\begin{array}{l}4 \text { (false } \\
\text { positive) }\end{array}$ \\
\hline abnormal & 69 & 20 (false negative) & $\begin{array}{l}49 \text { (true } \\
\text { positive) }\end{array}$ \\
\hline
\end{tabular}

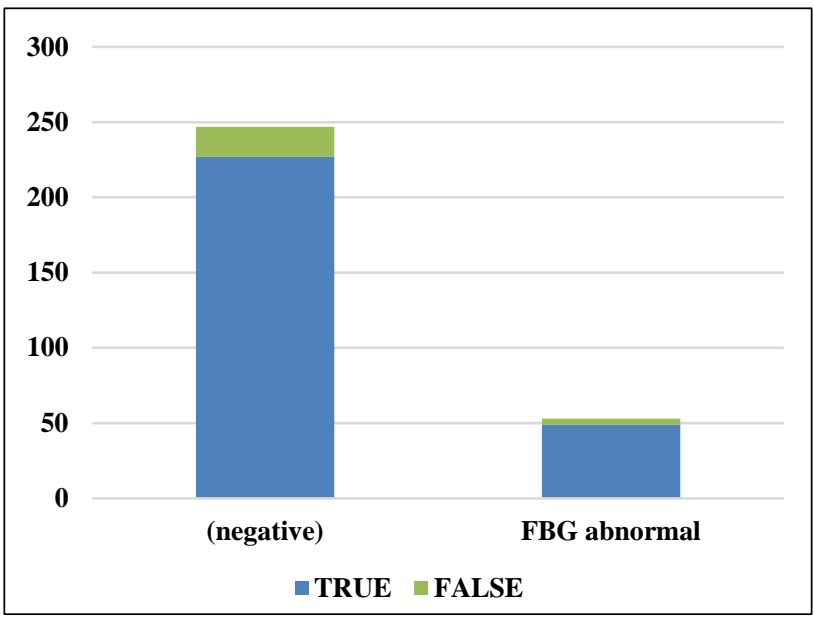

Figure 3: FBG test evaluation.

Table 4: Efficacy of fasting blood glucose test.

\begin{tabular}{|lll|}
\hline Statistical measures & Value & $95 \%$ CI \\
\hline Sensitivity & $71.01 \%$ & $58.84 \%$ to $81.31 \%$ \\
\hline Specificity & $98.27 \%$ & $95.63 \%$ to $99.53 \%$ \\
\hline Positive predictive value & $92.45 \%$ & $82.09 \%$ to $97.04 \%$ \\
\hline $\begin{array}{l}\text { Negative predictive } \\
\text { value }\end{array}$ & $91.90 \%$ & $88.69 \%$ to $94.26 \%$ \\
\hline Accuracy & $92.00 \%$ & $88.33 \%$ to $94.81 \%$ \\
\hline
\end{tabular}

\section{DISCUSSION}

PCOS is a common chronic condition with implications for morbidities, both in short term (subfertility and pregnancy related complications) and long-term complications (type 2 diabetes, cardiovascular disease, depression, poor quality of life and overall morbidity).

Insulin resistance appears to be the central pathophysiological mechanism responsible for various complications of PCOS and it is present in both lean and obese women. Insulin resistance may eventually lead to the development of hyperglycemia and Type 2 diabetes. ${ }^{10}$

Several mechanisms have been postulated to account for the predisposition to the glucose abnormalities among women with PCOS. Dunaif A et al, demonstrated that women with PCOS are insulin resistant, independent of obesity. ${ }^{11}$ Although the nature of insulin resistance in PCOS is currently unclear, defects in insulin receptor or post receptor signal transduction, altered adipocyte lipolysis, decreased glucose transporter 4 in adipocyte and impaired release of a D- chiro - inositol mediator have all been implicated. ${ }^{12-15}$ Furthermore, many women with PCOS exhibit beta cell dysfunction rendering insulin response to a glucose load insufficient for the degree of insulin resistance in PCOS. ${ }^{16}$ Approximately 30-40\% of women with PCOS have impaired glucose tolerance and 7.5 to $10 \%$ have type 2 diabetes. In a study on 168 PCOS adolescent girls in India, 36\% had impaired glucose tolerance and $9 \%$ had diabetes. ${ }^{17}$ In one meta-analysis, an increased risk of metabolic syndrome was found in PCOS women as compared to BMI matched controls, and this increased risk is persisted in lean women. ${ }^{18}$ The risk of impaired glucose tolerance and Type 2 diabetes is increased 5 to 7 fold in PCOS. In this study, the prevalence of glucose abnormalities was $23 \%$. In a study by Legro RS et al, normal glucose tolerance was seen in $61.4 \%$, IGT in $31.1 \%$ and diabetes in $7.5 \%$. Consistently diabetes was 4 times higher in a recent Danish registry and was diagnosed 4 years earlier. ${ }^{19,20}$

Whilst guidelines consistently recommend screening for glucose abnormalities in PCOS, whether to target subgroups, which test to use and optimal frequency vary between guidelines and remain controversial. ${ }^{21}$ Some recommend screening all women with PCOS where as others consider additional risk factors including ethnicity, BMI, previous history of gestational diabetes, family history of type 2 diabetes. ${ }^{22}$ In high risk, South Asians PCOS significantly impacts incidence of type 2 diabetes. ${ }^{23}$ Regardless of age the prevalence of gestational diabetes, IGT and type 2 diabetes are significantly increased in PCOS with risk independent of yet exacerbated by obesity. Therefore, effective methods of screening and early detection of glucose abnormalities is imperative in the management of women with PCOS. In this study, the mean age of women with glucose abnormalities is higher $(27.99 \pm 4.3)$ than the women with normal glucose values $(24.7 \pm 3.2)$, the difference seems to be statistically significant $(\mathrm{p}<0.01)$. Similarly, the mean BMI of women with glucose abnormalities is higher $(27.42 \pm 0.88)$ than the women with normal glucose values (23.36 \pm 0.7$)$, this difference also statistically significant ( $p$ $<0.01$ ). Legro R et al, also showed that an increased risk of IGT in women with advanced age, increased BMI, which are identical risk factors for the general population in developing IGT. In a cross-sectional study of 91 women with PCOS by 24. Trolle B et al, women who were older and had a higher BMI were more likely to have elevated fasting glucose values. ${ }^{24}$ In this study, a positive correlation was found between menstrual irregularities, family history and hirsutism/acne. Ehrmann DA et al, found that those diagnosed with type 2 diabetes were 2.6 times more likely to have a first degree relative with diabetes than women with normal glucose tolerance. ${ }^{25}$ Ehramnn DA et al, in a separate study evaluating a population of 408 premenopausal women with PCOS, also found a family history of type 2 diabetes in a first degree relative to be associated with a significantly higher risk for IGT and Type 2 diabetes in 
women with PCOS. Burghan GA et al, found a positive correlation of hyperandrogenism with hyperinsulinism. ${ }^{26}$

Several studies have documented the prevalence of IGT and type 2 diabetes in women with PCOS. It is estimated that IGT is present in $31-35 \%$ of women with PCOS. In addition, type 2 diabetes classified according to WHO criteria is present in $7.5 \%-10 \%$ of women with PCOS. In Indian populations, women with PCOS appear to have worse glucose intolerance than Caucasian populations. ${ }^{27}$ The enhanced rate of deterioration in glucose tolerance was corroborated by Legro $\mathrm{R}$ et al, who assessed the changes in glucose tolerance over time in U.S. women with PCOS and 23 control women who had baseline normal glucose tolerance. ${ }^{35}$

In this study, glucose abnormalities were found in 69 (23\%) women with 2 hours OGTT but only in 49 (16\%) women with FBG values alone. The sensitivity of FBG in assessing glucose abnormalities in PCOS women was lower $71.01 \%$, (95\% CI $58.84 \%$ to $81.31 \%$ ) and the specificity is $98.27 \%$ (95\% CI $95.63 \%$ to $99.53 \%$ ). Presently, the only screening method of identifying individuals with IGT is by an OGTT. ${ }^{28} \mathrm{~A}$ position statement of the Androgen Excess Society concluded that all patients with PCOS be screened for IGT with a 2 hours oral glucose tolerance test. It is more sensitive and moderately more specific in diagnosing glucose abnormalities compared with $\mathrm{FBG} .^{29}$ In addition to providing information on both beta cell secretion and peripheral insulin action, the OGTT provides a better assessment of IGT than homeostatic techniques such as fasting glucose to insulin ratio, fasting insulin and homeostatic model assessment. ${ }^{30}$ FBG has been classified as an insufficient screening tool in a recent systematic review on previous small studies in PCOS women by Tomlinson $\mathrm{J}$ et al. ${ }^{31}$ A study by Legro $\mathrm{R}$ et al, found that FBG values are poor predictors of diabetes and found that FBG criteria recommended for diabetes screening by ADA is not applicable to PCOS women as it missed 58\% of diabetes women in their study. ${ }^{3}$ David CWL, in a study showed that FBG has $79 \%$ sensitivity in detecting glucose abnormalities in PCOS women. ${ }^{32}$ In this study, also around one third of women with glucose abnormalities would be missed using FBG alone. Though OGTT has higher cost and greater inconvenience yet can define IGT and influence practice around lifestyle intervention and pharmacological treatment with clear evidence of type 2 diabetes prevention, not yet demonstrated based on FBG or HbA1c criteria. ${ }^{33,34}$

\section{CONCLUSION}

Women with PCOS are at an increased risk of developing impaired glucose tolerance and type 2 diabetes. Therefore, screening and detecting these glucose abnormalities is imperative in the management of PCOS women. The prevalence of glucose abnormalities was $23 \%$ with OGTT in this study population. The sensitivity of FBG in detecting glucose abnormalities is low compared to OGTT. Increasing age, higher BMI, menstrual abnormalities, hirsutism/acne, family history of diabetes have positive linear correlation with glucose abnormalities in women with PCOS.

Funding: No funding sources Conflict of interest: None declared

Ethical approval: The study was approved by the Institutional Ethics Committee

\section{REFERENCES}

1. Boomsma CM, Eijkemans MJ, Hughes EG, Visser GH, Fauser BC, Macklon NS. A meta-analysis of pregnancy outcomes in women with polycystic ovary syndrome. Human Repro Update. 2006;12(6):67383.

2. Apridonidze T, Essah PA, Iuorno MJ, Nestler JE. Prevalence and characteristics of the metabolic syndrome in women with polycystic ovary syndrome. J Clin Endocrinol Metab. 2005;90(4):1929-35.

3. Legro RS, Kunselman AR, Dodson WC, Dunaif A. Prevalence and predictors of risk for type 2 diabetes mellitus and impaired glucose tolerance in polycystic ovary syndrome: a prospective, controlled study in 254 affected women. J Clin Endocrinol Metab. 1999;84(1):165-9.

4. Deeks AA, Gibson-Helm ME, Paul E, Teede HJ. Is having polycystic ovary syndrome a predictor of poor psychological function including anxiety and depression?. Human Repro. 2011;26(6):1399-407.

5. Tominaga M, Eguchi HI, Manaka HI, Igarashi K, Kato TA, Sekikawa AK. Impaired glucose tolerance is a risk factor for cardiovascular disease, but not impaired fasting glucose. Funagata Diab Study. Diab Care. 1999;22(6):920-4.

6. Eshre TR. ASRM-sponsored PCOS consensus workshop group. revised 2003 consensus on diagnostic criteria and long-term health risks related to polycystic ovary syndrome. Fertility Sterility. 2004;81(1):19-25.

7. Ferriman DA, Purdie AW. The aetiology of oligomenorrhoea and/or hirsuties: a study of 467 patients. Postgrad Med J. 1983;59(687):17-20.

8. Misra A, Chowbey P, Makkar BM, Vikram NK, Wasir JS, Chadha D, et al. Consensus statement for diagnosis of obesity, abdominal obesity and the metabolic syndrome for Asian Indians and recommendations for physical activity, medical and surgical management. JAPI. 2009;57(2):163-70.

9. American Diabetes Association. Standards of medical care in diabetes. Diab Care. 2015;38(1):S193.

10. Kenny SJ, Aubert RE, Geiss LS. Prevalence and incidence of NIDDM. In: Harris MI, eds. Diabetes in America. Washington DC: US National Institutes of Health, NIH publication;1995:179-220. 
11. Dunaif A, Segal KR, Futterweit W, Dobrjansky A. Profound Insulin resistance, independent of obesity in PCOS. Diab. 1989;38:1165-74.

12. Dunaif A, Segal KR, Shelley DR, Green G, Dobrjansky A, Licholai T. Evidence for distinctive and intrinsic defects in insulin action in polycystic ovary syndrome. Diab. 1992;41(10):1257-66.

13. Ek I, Arner P, Bergqvist A, Carlstrom K, Wahrenberg H. Impaired adipocyte lipolysis in nonobese women with polycystic ovary syndrome: a possiblelink to insulin resistance? J Clin Endocrinol Metab. 1997;82:1147-53.

14. Rosenbaum D, Haber RS, Dunaif A. Insulin resistance in polycystic ovary syndrome: decreased expression of GLUT-4 glucose transporters in adipocytes. Am J Physio. 1993;264(2): E197-E202.

15. Nestler JE, Jakubouuicz DJ, Reamer P, Gunn RD, Allan G. Ovulatory and metabolic effects of D-chiroinositol in the polycystic ovary syndrome. N Engl J Med. 1999;340:1314-20.

16. Dunaif A, Finegood DT. Beta cell dysfunction independent of obesity and glucose intolerance in polycystic ovary syndrome. J Clin Endocrinol Metab. 1996;81:942-7.

17. Ganie MA, Khurana ML, Eunice M, Guptha M, Dwivedi S, Gulati M, et al. Prevalence of glucose intolerance among adolescents and young women with PCOS in India. Ind $\mathrm{J}$ Clin Endocrinol Metab. 2004:6:9-14.

18. Moran LJ, Misso ML, Wild RA, Norman RJ. Impaired glucose tolerance, type $2 \mathrm{DM}$ and metabolic syndrome. A systematic review and metaanalysis. Hum Reprod Update. 2010:16(4):34763.

19. Legro RS, Kunselman AR, Dodson WC, Dunaif A. Prevalence and predictors of risk for type $2 \mathrm{DM}$ and IGT in PCOS. A prospective controlled study in 254 affected women. J Clin Endocrinol Metab. 1999:84:165-9.

20. Rubin KH, Glintborg D, Nybo M, Abrahamsen B, Andersen M. Development and risk factors of type 2 diabetes in a nationwide population of women with polycystic ovary syndrome. J Clin Endocrinol Metab. 2017;102(10):3848-57.

21. Pelanis R. The prevalence of Type $2 \mathrm{DM}$ is not increased in normal weight women with PCOS. Human reproduction (Oxford, England), 2017.32(11):1-8.

22. Teede HJ, Misso ML, Deeks AA, Moran LJ, Stuckey BG, Wong JL, et al. Guideline Development Groups. Assessment and management of polycystic ovary syndrome: summary of an evidence-based guideline. Med J Aus. 2011;195:S65-112.

23. Kakoly NS. Ethnicity, obesity and prevalence of IGT and Type 2 DM in PCOS: a systamatic review and meta regression. Human Repro Update. 2018.
Available

at:

https://academic.oup.com/humupd/article-

abstract/24/4/455/4953995?redirectedFrom=fulltext

24. Trolle B, Lauszus FF. Risk factors for glucose intolerance in Danish women with PCOS. Acta Obstet Gynecol Scand. 2005;84:1192-6.

25. Ehrmann DA, Barnes RB, Rosenfield RL, Cavaghan MK. Imperial $\mathbf{J}$ Prevalence of impaired glucose tolerance and diabetes in women with polycystic ovary syndrome. Diab Care. 1999;22:141-6.

26. Burghan GA, Givens JR, Kitabachi AE. Corelation of hyperandrogenism with hyper insulinism in PCOD. J Clin Endocrinol Metab. 1980:50:113-6.

27. Norman RJ, Mahabeer S, Masters S. Ethnic differences in insulin and glucose response to glucose between white and Indian women in polycystic ovary syndrome. Fertil Steril. 1995;63:5862.

28. World Health Organisation 2006 definition and diagnosis of Diabetes Mellitus and intermediate hyperglycemia: report of a WHO/IDF consultation. Geneva: WHO. Available at: https://www.who.int/diabetes/publications/diagnosis diabetes2006/en/

29. American Diabetes Association. Standards of medical care in diabetes-2007. Diab Care. 2007;30(1):S4-1.

30. Legro RS, Castracane VD, Kauffman RP. Detecting insulin resistance in polycystic ovary syndrome: purposes and pitfalls. Obs Gynecol Survey. 2004;59(2):141-54.

31. Tomlinson J, Millward A, Stenhouse E, Pinkney J. Type 2 diabetes and cardiovascular disease in polycystic ovary syndrome: what are the risks and can they be reduced?. Diab Med. 2010;27(5):498515.

32. Lau DC. Screening for diabetes in women with polycystic ovary syndrome. CMAJ. 2007;176(7):951-2.

33. Knowler WC, Barrett-Connor E, Fowler SE, Hamman RF, Lachin JM, Walker EA, et al. Reduction in the incidence of type 2 diabetes with lifestyle intervention or metformin. New Eng J Med. 2002;346(6):393-403.

34. American Diabetes Association. Standards of medical care in diabetes-2017. Diab Care. 2017;40(1).

35. Legro RS, Gnatuk CL, Kunselman AR, Dunaif A. Changes in glucose tolerance over time in women with polycystic ovary syndrome: a controlled study. J Clin Endocrinol Metab. 2005 Jun 1;90(6):3236-42.

Cite this article as: Mohanapu S, Jeyakumar AM. Prevalence of glucose abnormalities in polycystic ovary syndrome women and evaluating the efficacy of fasting blood glucose in detecting these glucose abnormalities compared to glucose tolerance test. Int J Reprod Contracept Obstet Gynecol 2019;8:1751-6. 